\title{
Indo-China
}

\section{Republic of Vietnam}

Three medical teams and one mobile team are now at work in the Republic of Vietnam.

As mentioned in our last issue, an operation was launched for ten thousand Cambodians who had sought refuge in the Ha Tien area. A team of the German Red Cross of the Federal Republic of Germany has started work in co-operation with the Vietnamese National Society. The other West German team which was working in the Binh Tuy area has been replaced by another, again from the Federal Republic of Germany.

At Phu Bon, a French doctor is pursuing his activities for the Montagnard population and new refugees.

Lastly, a mobile team composed of two male nurse-technicians from the Federal Republic of Germany and the Norwegian medical adviser of the International Red Cross Assistance (IRCA) is carrying out a project for the boring of wells and the inspection of drinking water in refugee resettlement areas.

\section{Democratic Republic of Vietnam}

Prefabricated dwellings are continuing to be set up in the Democratic Republic of Vietnam, to house several thousand homeless. At Haiphong, for instance, fifty are going up for 300 families. These dwellings, which are supplied by Japan and specially intended for local climatic conditions, are assembled in a few days. A communal kitchen and bathroom unit is provided for every two houses. Workmen have been provided by the local administration. Ox-drawn carts, the traditional form of transport, are used for carrying particularly heavy items.

\section{Laos}

The Japanese team has concluded its mission at Pak Lay and is not being replaced. The clinical and prophylactic work will be carried on by the Laotian personnel. 
The malaria prevention campaign, conducted by a mobile French Red Cross team in co-operation with the Ministry of Health and the World Health Organization (WHO) in the Long Xien area, south of Luang Prabang, has been prolonged by a general systematic insecticide spraying operation.

\section{Khmer Republic}

After the flare-up of fighting in the Khmer Republic, particularly in the Kampot area, a Canadian Red Cross mobile medicosurgical team moved into the town's hospital at the end of May. In addition to caring for the wounded, it deals with numerous victims of the recent cholera outbreak.

The other teams, working at Kompong Thom, Kompong Chhnang and Svay Rieng, are also faced with an influx of wounded as a result of intensified fighting in past weeks. 